\title{
Mature Teratoma of the Filum Terminale in the Elderly, Incidentally Diagnosed after an Unmyelinated Lumbar Spine Trauma
}

\author{
Gabriela Florenţa Dumitrescu*,1, Lucian Eva², Maria-Raluca Munteanu², Mircea \\ Daniel Albert ${ }^{3}$, Bogdan Dobrovăţ ${ }^{3}$, Elena Cojocaru ${ }^{4}$, Ana-Maria Dumitrescu ${ }^{5}$, Anca \\ Sava $^{1,6}$
}

${ }^{1}$ Department of Pathology, "Prof. dr. N. Oblu" Emergency Clinical Hospital, laşi, ${ }^{2} \mathrm{II}^{\text {nd }}$ Clinic of Neurosurgery, "Prof. dr. N. Oblu" Emergency Clinical Hospital, laşi, ${ }^{3}$ Department of Radiology, "Prof. dr. N. Oblu" Emergency Clinical Hospital, laşi, ${ }^{4}$ Department of Pathology, "Grigore T. Popa" University of Medicine and Pharmacy, Iaşi, ${ }^{5}$ Faculty of Medicine, "Grigore T. Popa" University of Medicine and Pharmacy, laşi, ${ }^{6}$ Department of Anatomy and Embryology, "Grigore T. Popa" University of Medicine and Pharmacy, laşi, Romania

\begin{abstract}
Introduction: Spinal teratoma is an extremely rare entity as it represents $0.10-0.60 \%$ of all spinal tumors. It is mainly diagnosed during the first two decades of life and can be associated with spinal dysraphism.

Aim: To present a case of an asymptomatic mature teratoma of filum terminale, incidentally diagnosed in an elderly patient admitted to the Neurosurgery Department for multiple traumas after falling from 3 meters height.

Case description: A 76 year-old patient was admitted in the $2^{\text {nd }}$ Neurosurgery Department, "Prof. Dr. N. Oblu" Emergency Clinical Hospital, laşi with multiple traumas after falling from 3 meters height. The patient presented bilateral paresthesia of lower limbs and urinary incontinence. Radiography of the dorsal-lumbar spine column in emergency highlighted a dorsal - lumbar fracture (D12-L1) with medullar compression. MRI examination revealed a neoformation of filum terminale that filled almost the entire spinal canal, which had a composite, fatty and fluid structure, corresponding to L2-L4 and compressing the medullary cone. The neurosurgical decision was the excision of the entire neoformation. The histopathological examination of excised pieces revealed the presence of adipose tissue mixed together with striated and smooth muscle fibers, small and large cysts lined by various epithelia ranging from malpighian keratinized multilayered to simple ciliated columnar epithelium. No immature or malignant cells were identified and therefore the diagnosis was mature teratoma of filum terminale. The evolution of the patient was favorable with the remission of the neurological deficit.

Conclusions: Our patient is one of the oldest patients diagnosed up to date with a mature teratoma of filum terminale. Moreover, the location of neoformation at the lumbar (L2-L4) level is extremely rare. This case also highlights the fact that this mature teratoma was discovered by chance, when the patient came to the Neurosurgery Department for a spinal injury due to a falling from a tree.
\end{abstract}

Keywords: teratoma, filum terminale, spine trauma

Received: April 2014; Accepted after review: May 2014; Published: June 2014

${ }^{*}$ Corresponding author: Gabriela Florenta Dumitrescu, Department of Pathology, "Prof. Dr. N. Oblu" Emergency Clinical

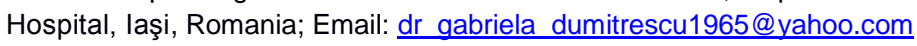




\section{Introduction}

150 years ago, Rudolf Virchow, "the father of modern pathology", described for the first time, in his Die krankhaften Geschwülste [1], an intraspinal "monstrous tumor" that was called teratoma. The etymology of this word was inspired by the grossly features of the lesion, as the Greek word "teratos" means "monster", and "onkoma" means a swelling or a tumor [2]. After nearly a century, Rupert A. Willis, a famous English embryologist and pathologist, defined this neoplasia in his Atlas of Tumor Pathology (AFIP) as "a true tumor or neoplasm composed of multiple tissues of kinds foreign to the part in which it arises" [3]. Nevertheless, it seems that the ancients were fascinated by this entity as the oldest reference of it was found in a Babylonian manuscript dating back over two thousand years $\left(6^{\text {th }}\right.$ century B.C.) that described the presence of this entity in a child [4].

A teratoma is characterized by the presence of many tissues derived from all three germ layers, having origin in a pluripotent stem cell existing in an early stage of embryo development. This entity is rarely identified in a spinal location, and it can be located extradural, intradural or intramedullary. This neoplasm is usually diagnosed in the first two decades of life and often ( $42 \%$ cases) it is associated with spinal malformations like syringomyelia or spina bifida, myelomeningocele, diastematomyelia or tethered cord $[5,6]$. Yet, adult patients do not present spinal dysraphism [7]. Depending on the location, the symptoms may vary, but they usually trigger neurological deficits.

We present a case of an asymptomatic mature teratoma of the filum terminale incidentally diagnosed to an elderly person who was admitted to the Neurosurgery Department with multiple traumas after an accidentally falling from a height.

\section{Case presentation}

\section{Clinical presentation}

A 76 year-old female patient was admitted to the $2^{\text {nd }}$ Neurosurgery Department, "Prof. Dr. N. Oblu" Emergency Clinical Hospital Iaşi, with bilateral paresthesias of lower limbs and urinary incontinence after multiple trauma caused by a free fall from 3 meters height, 48 hours ago.

\section{Radiological Features}

The NECT (non-enhanced computer tomography) examination revealed a fracture of the right transverse apophyses of the lumbar L1 vertebra and some moderate arthrosic changes (Fig. 1).

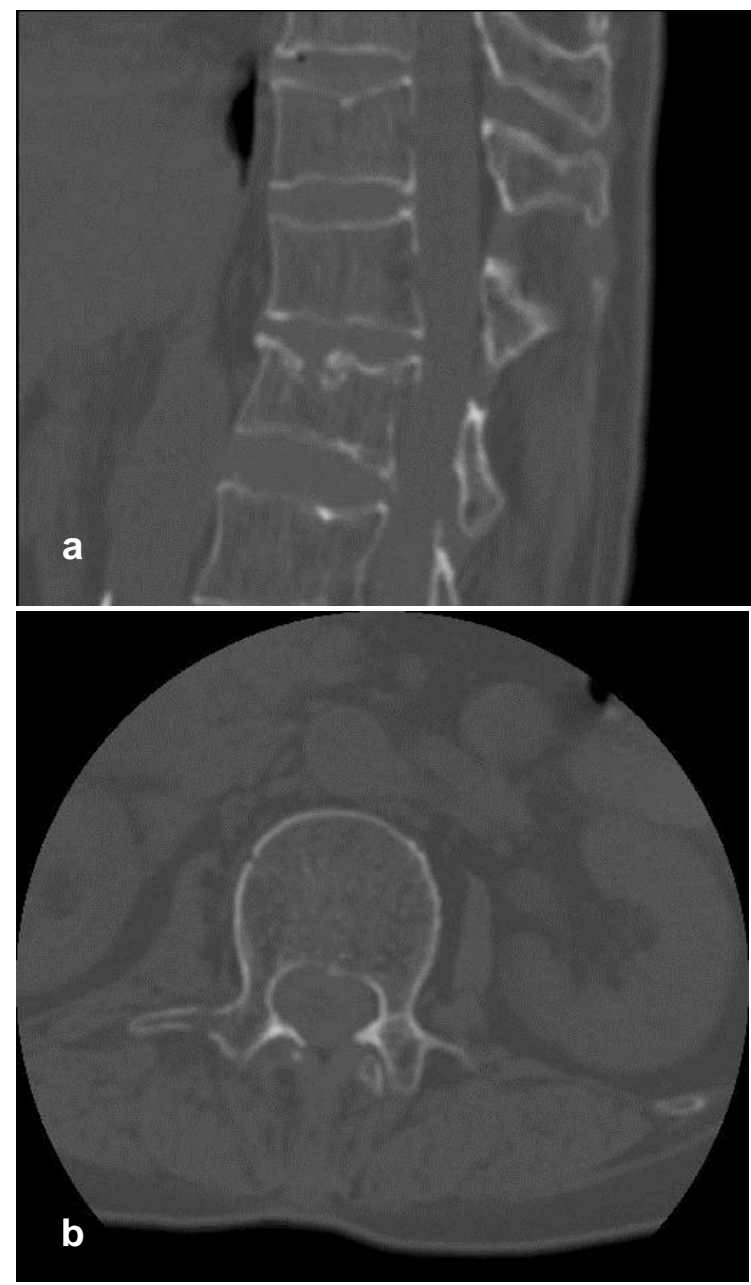

Fig. 1. NECT of the thoracal-lumbar (T11-L2) level: a) the sagital sections showed arthrosic changes with a median compression of L1 vertebra and some small marginal osteophytes; b) the axial section showed a fracture of the right transverse apophyses of the lumbar L1 vertebra.

After three days, the patient become paraplegic and a magnetic resonance imaging exam (MRI) of the lumbar spine identified a filum terminale tumor, occupying almost the entire spinal canal at the L2-L4 level, with a mixed structure (fatty and fluid) (Fig. 2). 


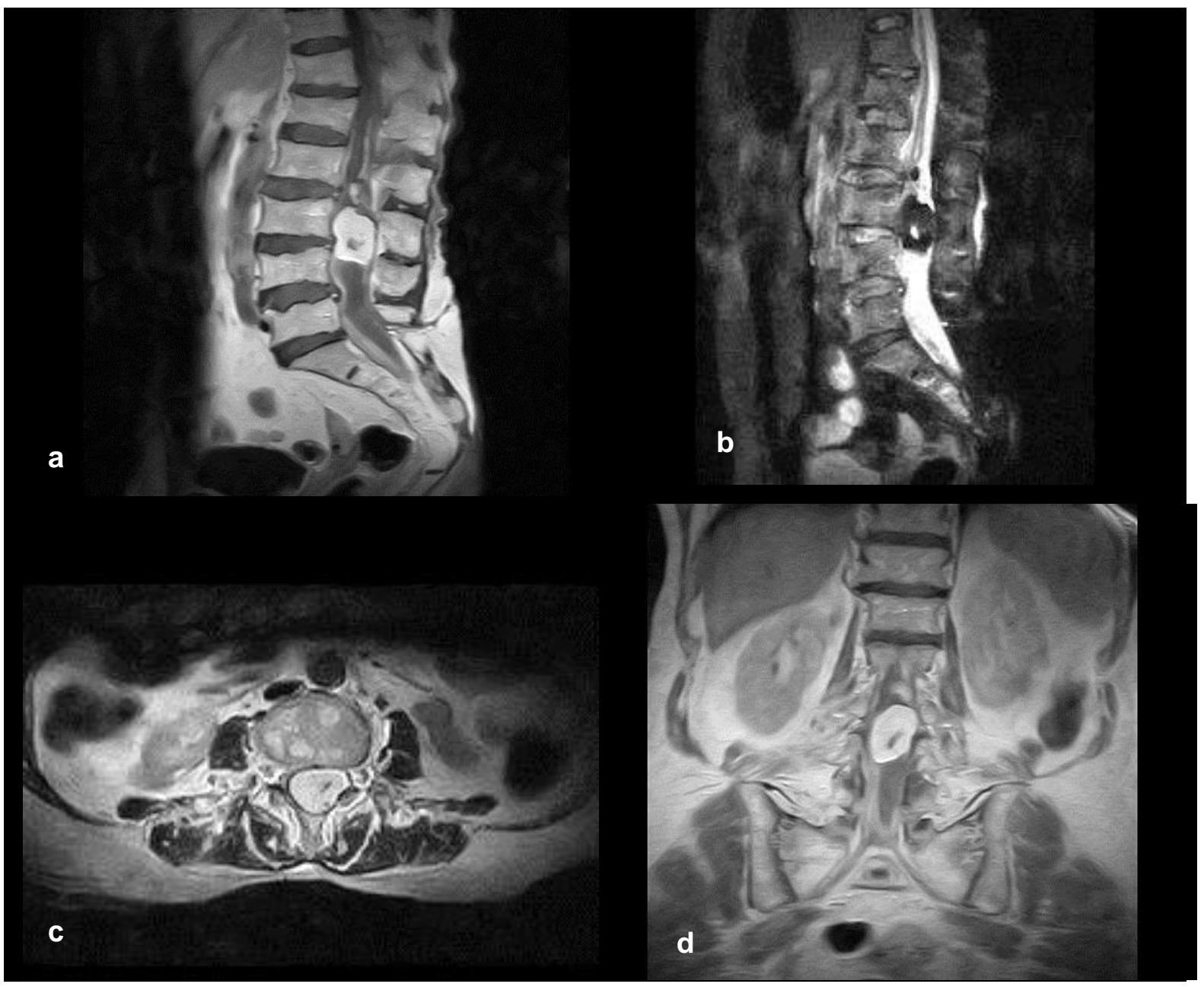

Fig. 2. Lumbar MR images after gadolinium: (a) sagital T1 image; (b) axial T2 image at L3 level; (c) coronary T1 image; (d) STIR (fat suppression) image: a filum terminale tumor, occupying almost the entire spinal canal at L2L4 level, with mixed structure (fatty and fluid).

The pre-operative examination of the patient revealed a specific pathology of an elderly: non-painful chronic ischemic cardiomyopathy, arterial hypertension, atherosclerosis, acute bronchitis and systemic osteoporosis.

\section{Cytohistomorphological Features}

Intraoperative consultation was requested for two surgical resection samples. The first smear cytology revealed adipose tissue with a relatively normal aspect and the second showed a malpighian keratinized multilayered epithelium. The cytopathological features triggered the suspicion of a mature teratoma.

The spinal tumor was totally excised and the tissue samples were discharged in a $10 \%$ formalin container and processed through the standard histopathological technique and stained with Hematoxylin and Eosin dyes (H\&E). After that, all formalin-fixed, paraffin- embedded tissue sections were immunostained with five primary antibodies [Polyclonal Rabbit anti-S100, dilution 1:400, DakoGlostrup, Denmark; Monoclonal Mouse Anti-Vimentin Clone Vim 3B4, dilution 1:100, DakoGlostrup, Denmark; anti-Desmin (dilution 1:50, DakoGlostrup, Denmark), anti-Human Cytokeratin Clones AE1/AE3 (dilution 1:400, DakoCarpenteria, USA), Policlonal Rabbit AntiGlial Fibrillary Acidic Protein (dilution 1:500, DakoGlostrup, Denmark)], using a two-step, non-avidin-biotin method (ENVISION ${ }^{\top \mathrm{M}}+$, Dako Corporation).

Histological examination revealed a heterogeneous entity consisting of two areas: a cystic and a solid one, both comprising a randomly disposed mixture of tissues with ectodermic, mesodermic, and endodermic origins, with histological structure different from that of the filum terminale (Fig. 3). 
Immunohistochemistry revealed positivity for anti-Desmin (showed striated and smooth muscle differentiation), anti-pan CK AE1/AE3 (revealed the epithelia), anti-GFAP (detected glial cells of the filum terminale, normally found in this region), anti-S100 (identified nerve fibers), and anti-Vimentin (detected dura mater, normally found in this region).

The final diagnosis was mature teratoma of filum terminale. It is noticeable that the postoperative evolution of the patient was positive, with partial remission of the neurological deficit.

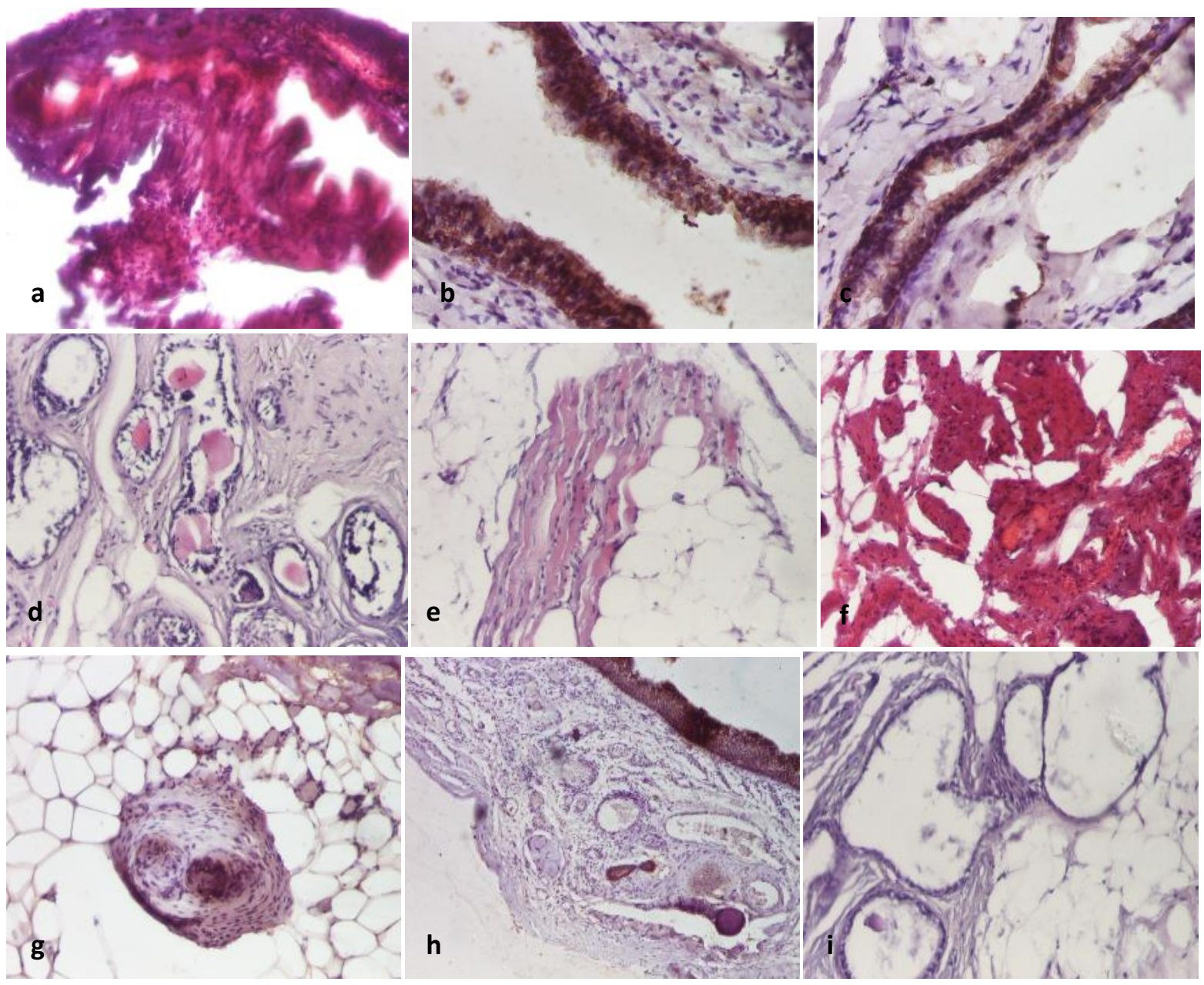

Fig. 3. Different tissues within the mature teratoma of filum terminale: tissues of endodermic origin: (a) pseudostratified ciliated columnar epithelium of respiratory type, HE x100; (b) same aspect, pan- CK x100; (c) simple stratified columnar epithelium with "goblet cells" and microvilli, intestine type, pan-CKx100; (d) thyroid follicles, HE x40; tissues of mesoderm origin: (e) striated muscle tissue included in adipose tissue, HEx100; (f) smooth muscle tissue, HEx100; tissues of ectoderm origin: (g) Pacini corpuscles, GFAPx100; (h) Microcysts lined by a 2-layer cubic epithelium, HEx100; (i) Cyst lined by malpighian keratinized multilayered epithelium sitting on a connective tissue layer with blood vessels, a sebaceous gland and a psammomatous body, pan-CK x40.

\section{Discussions}

Teratoma is one of nearly 100 histopathological subtypes of tumors included in the World Health Organization (WHO) classification of central nervous system tumors. It is listed among the germ cell tumors, together with germinoma, embryonic carcinoma, yolk sac tumor, endodermal sinus tumor, choriocarcinoma and mixed germ cells tumors [8].
Spinal teratoma is included in the category of extragonadal teratomas arising within the neuraxis, together with those developing in the pineal gland [9], sellar and suprasellar regions [10], third ventricle [11] or fourth ventricle [12].

There are few spinal teratomas diagnosed in adults, most of them being reported in literature $[7,13]$ as individual cases because there are only small series identified over a long period of time as their occurrence in this 
location is extremely rare, i.e. only $0.10-0.60 \%$ of all spinal tumors [13-18]. In 1999, Poeze et al. (6) reported only 83 cases of adults with spinal teratomas published at the time. Currently, there are no more than 100 cases, most of them being diagnosed during the $4^{\text {th }}$ $5^{\text {th }}$ decades of life [13]. In the last five years, there have been published some cases of intramedullary or intraspinal extramedullary teratomas diagnosed in old patients [19, 20], probably due to the increasing average human lifespan to the $8^{\text {th }}$ or $9^{\text {th }}$ decades of life. However, the oldest patient recorded with spinal teratoma is an 85 year-old man [21]. Our case is represented by a 76 year-old woman and we might consider her as one of the oldest patients with a spinal teratoma.

Clinically, the spinal teratoma causes persistent and progressive neurological deficits. In our case, the patient was suffering from moderate low-back pain for several years, associated with a sudden paraparesis after a lumbar spinal trauma following an accidental fall from a tree. Because the identification of the spinal teratoma presented in this paper was possible only after the occurrence of the lumbar trauma, we searched for similar cases in the medical literature. This situation is similar to that of a patient 85 years old presented by Stevens et al. in 2006 [21]. However, in the literature there are only three cases reported until now having an asymptomatic teratoma, mediastinally located, that were diagnosed after a car accident or a trauma caused by a blunt object [22 -24].

Computer-tomography (CT) and magnetic resonance images (MRI) are very useful in suggesting the diagnosis of a spinal teratoma, especially when a composite, solid and cystic lesion, with the existence of a fat-similar density and calcification areas are identified [7], thus proving the heterogeneous nature of this entity.

From histological point of view, the teratomas within the neuraxis are similar to the extragonadal ones, and consist of a mixture of cells derived from all three germ layers. Based on the microscopic features, they can be classified as mature (70\%), immature $(20 \%)$ and malignant (10\%) [25]. In fact, the pathological diagnosis is the major diagnostic tool. In our case, a teratoma has been suggested by the cytopathological examination due to the identification of tissues which are not normally present in the spine, i.e. malpighian keratinized multilayered epithelium associated with adipose tissue. Subsequently, the histopathological analysis of the resected formation showed a mixture of tissues originating from all three germ layers: the ectoderm (malpighian keratinized multilayered epithelium, Pacini corpuscles, sebaceous glands and sweat gland ducts), the mesoderm (striated muscle, non-striated muscle, adipose tissue, cartilage) and the endoderm (enteric epithelium with microvilli and mucinous cells, pseudostratified ciliated columnar epithelium of respiratory type, and thyroid epithelium). A complete and accurate diagnosis needed the analysis of many sections which included several tumoral areas, in order to identify possible focal signs of immaturity or malignancy. Finally, the immunohistochemical markers have been useful for the identification of various tissue components.

\section{Conclusions}

Our patient is one of the oldest patients diagnosed with mature teratoma of filum terminale, this case being particularly rare due to the location of the neoformation at the lumbar level (L2-L4) and due to the incidentally identification after a lumbar trauma because no neurological symptoms appeared during patient's life. 


\section{References}

1. Virchow R: Die krankhaften Geschwülste, Bd. I, August Hirschwtald, Berlin, 1863, p. 96.

2. Sinha CK, Davenport M (Eds.), Handbook of Pediatric Surgery, Springer-Verlag, London, 2010, p. 399.

3. Willis RA: Teratomas, in Atlas of Tumor Pathology, section III, Fascicle 9, Armed Forced Institute of Pathology, Washington, 1951.

4. Pantoja E, Rodríguez-lbañez I: Sacrococcygeal Dermoids and Teratomas, Am J Surg, 1976, 132:377-382.

5. Keating RF, Goodrich JT, Parker RJ: Tumors of the Pediatric Central Nervous System, Thieme Medical Publishers, New York, 2001

6. Poeze M, Herpers M, Tjandra B, Freling G, Beuls $E$ : Intramedullary spinal teratoma presenting with urinary retension: case report and review of the literature. Neurosurg, 1999, 45:379-385.

7. Sharma MC, Jain D, Sarkar C, et al: Spinal Teratomas: A Clinico-Pathological Study of 27 Patients. Acta Neurochir (Wien), 2009, 151(3):245-52.

8. Louis DN, Ohgaki H, Wiestler OD, Cavenee WK (Eds.), WHO Classification of Tumors of the Central Nervous System, 4th Edition, IARC, Lyon, 2007, pp. 201-202.

9. Friedman JA, Lynch JJ, Buckner JC, Scheithauer BW, Raffel C, Management of Malignant Pineal Germ Cell Tumors with Residual Mature Teratoma, Neurosurg, 2001, 48(3):518-22.

10. Sweiss RB, Shweikeh F, Sweiss FB, Zyck S, Dalvin L, Siddiqi J: Suprasellar Mature Cystic Teratoma: An Unusual Location for an Uncommon Tumor. Case Rep Neurol Med, vol. 2013, Article ID 180497, 4 pages, 2013. doi:10.1155/2013/180497.

11. Eckmann C, Hüneke B, Schlotfeldt TC, Carstensen MH, Reinhold S: Prenatal Diagnosis of Malignant Intracranial Teratoma in the Fetus, Geburtshilfe Frauenheilkd, 1991; 51(10):859-60.

12. Sanyal P, Barui S, Mathur S, Basak U: A Case of Mature Cystic Teratoma Arising from the Fourth Ventricle. Case Rep Pathol, 2013, 2013:702424. doi: 10.1155/2013/702424.

13. Agrawal M, Uppin MS, Patibandla MR, et al: Teratomas in the Central Nervous System: A Clinico - Morphological Study with Review of Literature, Neurol India, 2010, 58(6):841-846.
14. Fernández-Cornejo VJ, Martínez-Pérez M, PoloGarcía LA, Martínez-Lage JF, Poza M: Cystic Mature Teratoma of the FilumTerminale in an Adult Case Report and Review of the Literature, Neurocirugia (Astur), 2004, 15(3):290-3.

15. Sung KS, Sung SK, Choi HJ, Song YJ: Spinal Intradural Extramedullary Mature Cystic Teratoma in an Adult, $J$ Korean Neurosurg Soc, 2008, 44:334-337.

16. Hamabuchi M, Hasegawa R, Murase $T$ : Teratoma of the Spinal Cord. A Case Report with CT Scans, J Bone Joint Surg, 1989, 71$\mathrm{B}(3): 390-392$.

17. Jeong SJ, Youm JY, Choi SW, Kim SH: Intradural Mature Teratoma in the Lumbar Spine Found in Adult, Kor J Spine, 2009, 6(3):211-13.

18. Yu J, Qu L, Li Y, Huang H: Coexistence of Spinal Teratoma of the Conus Medullaris and Arteriovenous Malformations in an adult: A Case Report, Turk Neurosurg, 2012, 22(4):510-14.

19. Ijiri K, Hida K, Yano S, Iwasaki Y: Huge Intradural Ossification Caused by a Mature Spinal Teratoma: Case Report, Neurosurg, 2009, 64(6) E1200-1; discussion E1201.

20. Ghostine S, Perry E, Vaynman S, et al: The Rare Case of an Intramedullary Cervical Spinal Cord Teratoma in an Elderly Adult: Case Report and Literature Review, Spine (Phila Pa 1976), 2009, 34(26):E973-8.

21. Stevens QE, Kattner KA, Chen YH, Rahman MA: Intradural Extramedullary Mature Cystic Teratoma: not only a Childhood Disease, $J$ Spinal Disord Tech, 2006, 19(3):213-6.

22. Santos PC, Maia CP, Penha Pereira JC, de Alvarenga Oliveira TC: Giant Mediastinal Teratoma found during Surgery after Thoracic Trauma, Rev Bras Cir Cardiovasc, 2007, 22(2):252-4.

23. Yang WM, Chen ML, Lin TS: Traumatic Hemothorax Resulting from Rupture of Mediastinal Teratoma: A Case Report. Int Surg, 2005, 90(4):241-4

24. Miyazawa M, Yoshida K, Komatsu K, Kobayashi N, Haba Y: Mediastinal Mature Teratoma with Rupture into Pleural Cavity Due to Blunt Trauma. Ann Thorac Surg, 2012, 93(3):990-2.

25. Chowdhury MM, Pierro A: Sacrococcygeal teratoma, in Spitz L., Coran A.G. (Eds.), Operative Pediatric Surgery, $6^{\text {th }}$ Edition, Taylor \& Francis Group, 2006, p. 725. 